\title{
Research on Representation and Retrieval for Equipment Fault Information Based on Domain Ontology
}

\author{
Yongjie $\mathrm{Li}^{1, a}{ }^{\text {, }}$ Houxiang Wang ${ }^{2, b}$ and Jingjing Zhang ${ }^{3, \mathrm{c}}$ \\ ${ }^{1,2}$ Electronic Eng. College, Naval Univ. of Engineering, Wuhan Hubei 430033 China; \\ ${ }^{2}$ Naval Engineering Design and Research Inst., BeiJing 100070 China \\ acumtlyj@163.com, bwxh_hg@163.com, 'zjj_1977@163.com
}

Keywords:equipment maintenance; fault information; domain ontology

\begin{abstract}
Analyzed the shortcomings of fault informationmanagementin the field of warship equipment maintenance. An ontology-based method for equipment fault informationmodeling is proposed on the basis of the characteristics and the actual in warship equipment maintenance.The modelingprocess of equipment fault information ontology is introduced and the model is built using Protégé. In view of the lack of case retrieval based on keywords technology, the comprehensiveretrieval algorithm based pre retrieval is designed anda prototype system is developed, validated and applied. The results showed that the algorithm can greatly improve the precision of fault case retrieval.
\end{abstract}

\section{Introduction}

A large number of maintenance knowledgeareaccumulated in the process of warship equipment maintenance and support. Atpresent,the main using of the maintenance knowledge is building fault case systems in order to manage, retrieve and utilize fault information (called fault cases). However,there are lots of shortcomings in using fault cases such as the low effective management andthe low ability of sharing, reusing and case reasoning because of the lack of unified canonical representation in different equipment fault information management systems.

For his better concept hierarchical structure, logical reasoning ability and ability to express knowledge,ontology technology has been extensively used in many knowledge managementfields such as medical diagnosis,product design and manufacturing etc.[1]. To provide effective guidance on work of equipment maintenance and support,this paper applies ontology theory into the equipment fault case knowledge management,explores the modeling representationmethodsand normative structure for equipment fault case knowledge and researches on equipment fault case knowledge retrieval algorithm.

\section{Fault case knowledge ontology construction}

There are many ontology description languages such as SHOE, XOL, RDF, OIL, OWL.W3C launched RDF (S), DAML+OIL and OWL as the standard for ontology description language. OWL is used as the main ontology description language for its good compatibility, interactivity and rich semantic expression ability [2].

The process of establishing the equipment maintenance fault case knowledge ontology generally includes the following stages:

1) Determine the scope and target of equipment fault case knowledge ontology;

2) Collect and analyzeequipment fault case knowledge;

3) Determine core concepts of equipment fault case knowledge;

4) Establish conception hierarchy of equipment fault case knowledge;

5) Define the concepts and attributes of equipment fault case knowledge;

6) Code and instantiate the equipment fault case ontology;

7) Examine and evaluate of equipment fault case ontology. 
The works of equipment maintenance are not only related to the management and maintenance unit, maintenance personnel, spare part, detection equipment, maintenance standard,technical data and documentation,maintenance cost etc. but also associated with the ontology warship, equipment and equipment system. The equipment fault case ontology concepts can be defined as follows.

Definition 1:The fault case ontology of equipment maintenance ,EMFCO for short . It can be defined as 9-tuple, EMFCO $\rightarrow\left\{\mathrm{I}_{\mathrm{C}}, \mathrm{D}_{\mathrm{C}}, \mathrm{T}_{\mathrm{C}}, \mathrm{E}_{\mathrm{C}}, \mathrm{M}_{\mathrm{C}}, \mathrm{P}_{\mathrm{C}}, \mathrm{C}_{\mathrm{C}}, \mathrm{H}_{\mathrm{C}}, \mathrm{R}_{\mathrm{C}}\right\}$.

Where $\mathrm{I}_{C}$ is basic information of fault case, $\mathrm{D}_{C}$ is the fault description, $\mathrm{T}_{C}$ is fault opportunity, $\mathrm{E}_{C}$ is fault influence, $M_{C}$ is the fault mode, $P_{C}$ is the fault parameters, $C_{C}$ is the fault cause, $H_{C}$ is the fault handling and $\mathrm{R}_{\mathrm{C}}$ is the fault resources.

Definition 2: Basic information of fault cases ontology, $\mathrm{I}_{\mathrm{C}}$ for short. It can be defined as 6-tuple. $\mathrm{I}_{\mathrm{C}} \rightarrow\left\{\mathrm{CID}_{\mathrm{I}}, \mathrm{SH}_{\mathrm{I}}, \mathrm{EP}_{\mathrm{I}}, \mathrm{PO}_{\mathrm{I}}, \mathrm{HT}_{\mathrm{I}}, \mathrm{RT}_{\mathrm{I}}\right\}$.

Where $\mathrm{CID}_{\mathrm{I}}$ is the fault case ID, $\mathrm{SH}_{\mathrm{I}}$ is the warship of fault; $\mathrm{EP}_{\mathrm{I}}$ is equipment of fault; $\mathrm{PO}_{\mathrm{I}}$ is the equipment system, $\mathrm{HT}_{\mathrm{I}}$ is the fault happen time and $\mathrm{RT}_{\mathrm{I}}$ is the fault repaired time.

Definition 3: Cause of fault case, $C_{C}$ for short. $C_{C}$ can be defined as 3-tuple. $C_{C} \rightarrow\left\{C_{C}, M_{C}\right.$, $\left.\mathrm{RA}_{\mathrm{C}}\right\}$.

Where $\mathrm{CG}_{\mathrm{C}}$ is the fault category, $\mathrm{MH}_{\mathrm{C}}$ is the failure mechanism and $\mathrm{RA} \mathrm{A}_{\mathrm{C}}$ is the cause analysis.

Definition4: Handling of fault case, $\mathrm{H}_{\mathrm{C}}$ for short. It can be designed as 3-tuple. $\mathrm{H}_{\mathrm{C}} \rightarrow\left\{\mathrm{TM}_{\mathrm{S}}, \mathrm{QU}_{\mathrm{S}}, \mathrm{EV}_{\mathrm{S}}\right\}$.

Where $\mathrm{TM}_{\mathrm{S}}$ is the troubleshooting methods, $\mathrm{QU} \mathrm{S}_{\mathrm{S}}$ is maintenance quality and $\mathrm{EV}_{\mathrm{S}}$ is the maintenance evaluation.

The concept and attribute modeling representation of equipment fault case used by Protégé-4.3 is shown as Fig. 1.

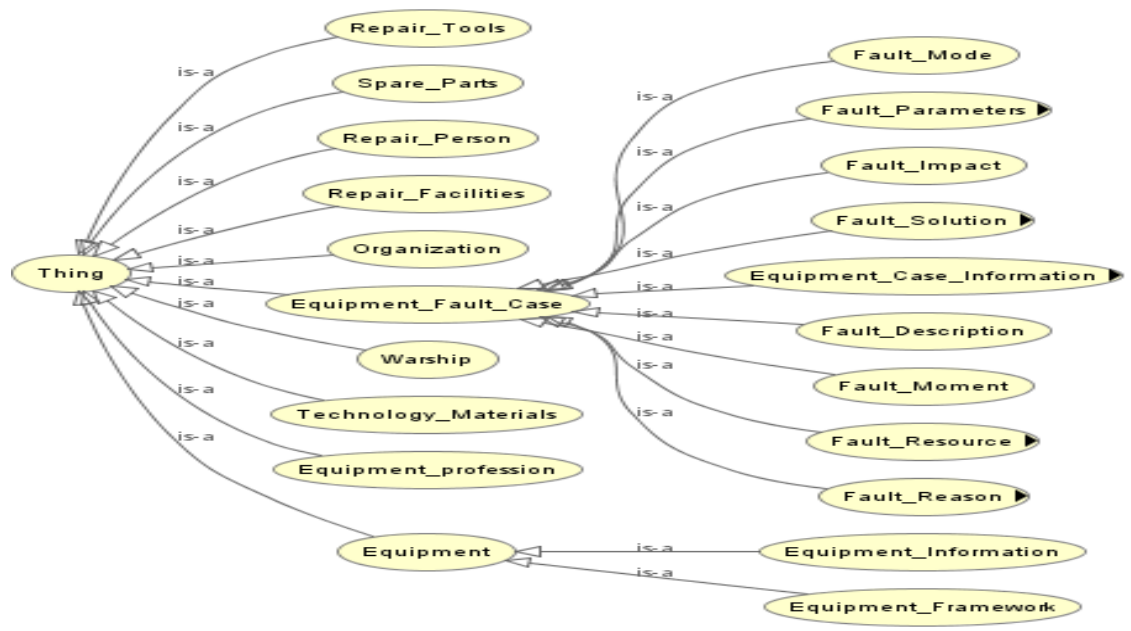

Fig. 1. Concept and attribute model of equipment fault case

In addition to the common Kind-of relation, Part-of relation and Equivalent-of relation, the relationships between the concepts of fault case knowledgeontologyalso includes other types of relationships, such asbelong-to relationship between maintenance personnel and institution(inverserelation is Have-of), the Use-to relation between maintenance tools and equipment fault (inverse relation is Use-of), the Has-errorrelation between equipment and fault case(inverse relation Error-of), the Repair-of relation between maintenance personnel and equipment (inverse relation is Repaired-by) and the Consumption-of relation between spare parts andfault case(inverse relation is Consumed-by) etc..

\section{Fault case knowledge retrieval}

The retrieval and matching algorithms are very important for maintenance personnel can quickly retrieve the fault case knowledge. The equipment fault case knowledge involves conceptual information,numerical information and text description information. We can't accurately retrieve fault case knowledge only use one of them. So in this paper, we put forward a comprehensive fault case knowledge retrieval algorithm based on pre-retrieval. 
In order to reduce the scale of fault caseretrieval spatial and improve the efficiency of fault case retrieval, we conducted a preliminary filtering of fault case base through the method of matching theclearattributes of fault case, such as warship name, equipment professional, equipment name,equipmentsystem etc..This paper uses SPARQL language to realize the fault case filtering[3].

Similarity calculation of fault case is divided intolocal similarity and the overall similarity.The local similarity is the similarity of a vector attribute between the fault case be retrieved and the fault case in case base. The overall similarity is the similarity value between the fault case be retrieved and the fault case in case base, which is calculated as the sum of weighted local similarity. The fault cases in case base are selected when it's overall similarityis greater than the threshold which is set by domain experts or system users[4].

The vector attribute in the fault caseis mainly divided into numerical type, string type, enum, boolean type and ontology type. This paper focuses on the similarity calculation of digital type, string type and ontology type.

We suppose $C_{i}$ is a fault case in fault case base which is indicated by $n$ attributes, namely $C_{i}=\left(x_{i 1}, x_{i 2}, x_{i 3}, \ldots, x_{i n}\right)$. Where $x_{i j}$ is the $j^{\text {th }}$ attribute of $C_{i}$. Qis the fault case be queried, where $y_{j}$ is $\mathrm{j}^{\text {th }}$ attribute of Qcorresponding tox $\mathrm{x}_{\mathrm{ij}}$.

(1) Similarity calculation of numerical type feature value

We define $y_{j}$ is a numericial attribute of a new fault case $Q$ and $x_{i j}$ is the corresponded attribute of a fault case in fault case base.There are three types of $y_{j}$ value: definite number, interval number and fuzzy number.

1) When $y_{j}$ is a definite number, the attribute similarity $\operatorname{Sim}_{i}\left(s_{j}\right)$ can be calculated according to Eq. 1.

$\mathrm{d}\left(\mathrm{C}_{\mathrm{ij}}, \mathrm{Q}_{\mathrm{j}}\right)$ is the distance of two fault cases and its value is

$$
\operatorname{Sim}_{i}\left(s_{j}\right)=\frac{1}{1+d\left(C_{i j}, Q_{j}\right)}
$$

$$
d\left(C_{i j}, Q_{j}\right)=\left\{\begin{array}{l}
\frac{\left|x_{i j}-y_{j}\right|}{\max \left(x_{j}\right)-\min \left(x_{j}\right)} \max \left(x_{j}\right)-\min \left(x_{j}\right) \neq 0 \\
\frac{\left|x_{i j}-y_{j}\right|}{\left|x_{i j}\right|} \max \left(x_{j}\right)-\min \left(x_{j}\right)=0 \text { and } x_{i j} \neq 0 \\
\left|x_{i j}-y_{j}\right| \max \left(x_{j}\right)-\min \left(x_{j}\right) \neq 0 \text { and } x_{i j} \neq 0
\end{array}\right.
$$

$\max \left(\mathrm{x}_{\mathrm{j}}\right)$ andmin $\left(\mathrm{x}_{\mathrm{j}}\right)$ are the maximum and minimum values of $\mathrm{x}_{\mathrm{j}}$ in fault case base.

2) When $y_{j}$ is a interval number, the attribute similarity $\operatorname{Sim}_{i}\left(s_{j}\right)$ can be calculated according toEq. 3.

$$
\operatorname{Sim}_{i}\left(s_{j}\right)=\left\{\begin{array}{lr}
1 & x_{i} \in y_{j} \\
\frac{1}{1+d\left(C_{i j}, Q_{j}\right)} & x_{i} \notin y_{j}
\end{array}\right.
$$

$\mathrm{d}\left(\mathrm{C}_{\mathrm{ij}}, \mathrm{Q}_{\mathrm{j}}\right)=\min \left(\left|\mathrm{x}_{\mathrm{ij}}-\mathrm{y}_{\mathrm{ja}}\right|,\left|\mathrm{x}_{\mathrm{ij}}-\mathrm{y}_{\mathrm{jb}}\right|\right), \mathrm{y}_{\mathrm{ja}}$ and $\mathrm{y}_{\mathrm{jb}}$ are the endpoint values of $\mathrm{y}_{\mathrm{j}}$.

3) wheny $_{j}$ is a fuzzy value and it can be shaped like "relation operator $+v$ ", where $v$ is the target value, the attribute similarity $\operatorname{Sim}_{\mathrm{i}}\left(\mathrm{s}_{\mathrm{j}}\right)$ can be calculated according toEq. 4 .

tis the true value of $x_{j}$ in fault case base.

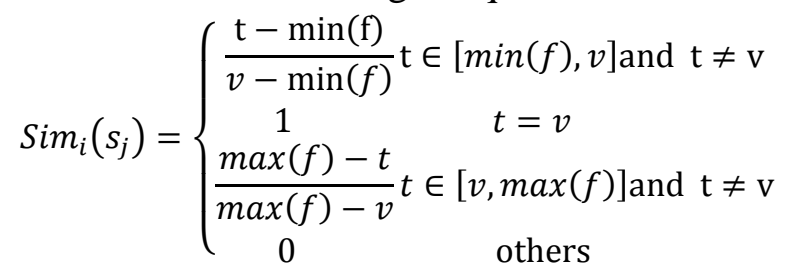

(2) Similarity calculation of string type feature value

In order to improve the matching accuracy, string feature vectorcan be constructed and its elements are the frequency of a certain keywords in the string.The similarity can be calculated by calculating the two vector distance. 
We define $\mathrm{x}_{\mathrm{ij}}$ and $\mathrm{y}_{\mathrm{j}}$ are the values of the two strings be compared. $\mathrm{K}=\left\{\mathrm{k}_{1}, \mathrm{k}_{2}, \mathrm{k}_{3}, \ldots, \mathrm{k}_{\mathrm{m}}\right\}$, the keyword $\mathrm{k}_{\mathrm{i}}$ is composed of ontology vocabularies and terminologies.

$\mathrm{V}_{1}=\left\{\mathrm{xv}_{1}, \mathrm{xv}_{2}, \mathrm{xv}_{3}, \ldots, \mathrm{xv}_{\mathrm{m}}\right\}, \mathrm{V}_{1}$ is the feature vector constructed by $\mathrm{x}_{\mathrm{ij}}, \mathrm{xv}_{\mathrm{i}}$ is the frequency of $\mathrm{k}_{\mathrm{i}}$ in $\mathrm{x}_{\mathrm{ij}}$.

$\mathrm{V}_{2}=\left\{\mathrm{yv}_{1}, \mathrm{yv}_{2}, \mathrm{yv}_{3}, \ldots, \mathrm{yv}_{\mathrm{m}}\right\}, \mathrm{V}_{2}$ is the feature vector constructed by $\mathrm{y}_{\mathrm{j}}, \mathrm{yv}_{\mathrm{i}}$ is the frequency of $\mathrm{k}_{\mathrm{i}}$ in $\mathrm{y}_{\mathrm{j}}$.

The similarity $\operatorname{Sim}_{\mathrm{i}}\left(\mathrm{s}_{\mathrm{j}}\right)$ can be calculated according to Eq. 5.

(3)Similarity calculation of ontology type

$$
\operatorname{Sim}_{i}\left(s_{j}\right)=\sum_{i=1}^{m} x v_{i} \times y v_{i} / \sqrt{\sum_{i=1}^{m} x v_{i}^{2}} \sqrt{\sum_{i=1}^{m} y v_{i}^{2}}
$$

Thefault case knowledge are classified and defined as tree structure in the previouschapters. Eachconceptand instance is a tree node of the fault case knowledge ontology. Whenthe attribute value is the ontology instances,the similarity can be calculated by calculating the distance of the node in tree structure, as shown in Eq. 6.

$$
\operatorname{Sim}_{i}\left(s_{j}\right)= \begin{cases}\frac{2 \times D e p\left(\operatorname{Msc}\left(x_{i j}, y_{j}\right)\right)}{\operatorname{Dis}\left(x_{i j}, y_{j}\right)+2 \times D \operatorname{Dep}\left(\operatorname{Msc}\left(x_{i j}, y_{j}\right)\right)} x_{i j} \neq y_{j} \\ 1 & x_{i j}=y_{j}\end{cases}
$$

$\operatorname{Msc}\left(x_{i j}, y_{j}\right)$ is the nearest father node of $x_{i j}$ and $y_{j}$. Dep(Msc $\left.\left(x_{i j}, y_{j}\right)\right)$ isnode depth of $\operatorname{Msc}\left(x_{i j}, y_{j}\right)$ and $\operatorname{Dis}\left(\mathrm{x}_{\mathrm{ij}}, \mathrm{y}_{\mathrm{j}}\right)$ is the shortest distance between $\mathrm{x}_{\mathrm{ij}}$ and $\mathrm{y}_{\mathrm{j}}\left(\right.$ Minimum number of nodes from $\mathrm{x}_{\mathrm{ij}}$ to $\left.\mathrm{y}_{\mathrm{j}}\right)$.

(4)Theoverall similaritycalculation of fault case

The overall similarity $\operatorname{SSim}\left(\mathrm{C}_{\mathrm{i}}, \mathrm{Q}\right)$ between $\mathrm{Q}$ and $\mathrm{C}_{\mathrm{i}}$ can be calculated according to Eq. 7 .

$$
\operatorname{SSim}\left(C_{i}, \mathrm{Q}\right)=\frac{\sum_{j=1}^{n}\left(s w_{j} \times \operatorname{Sim}_{i}\left(s_{j}\right)\right)}{\sum_{j=1}^{n} s w_{j}}
$$

$\mathrm{sw}_{\mathrm{j}}$ is the weight of $\mathrm{j}^{\text {th }}$ attribute which can be determined by field experts or the AHP(Analytic Hierarchy Process) algorithm[5].

\section{Application example}

The fault case knowledge ontology is modeled by protégé 4.3. The attributes and relations between them are designed. More than 150 instances of fault case knowledge are extracted through the collection and arrangement of equipment maintenancematerials of anaval ship troopsin five years.

We build an prototype system using Eclipse,Java JDK and Jena as development platformand environment, Oracle11g as background database. Based on the communication with domain experts ,we set the weight of fault influence,fault mode, fault parameters, fault causation, fault solution etc. and fault case similarity threshold is 0.65. Comparedwith the traditional keyword retrieval model, the recall and precision of fault case are greatly improved.

\section{Summary}

Theconcepts, attributes and the relationsbetween them inequipment fault case knowledge are studied based on the analysis on the characteristics in the field of warship equipment maintenance and support. The knowledge model is built using Protégé. In view of the lack of case retrieval based on keywords technology, the comprehensiveretrieval algorithm based pre-retrieval was designed anda prototype system is developed, validated and applied. The results showed that the algorithm can greatly improve thecomprehensiveness and precision of fault case retrieval. The studyin this paper can provide technical method and basis for the equipment maintenance knowledge sharing, and improve the knowledge's sharing and reuse ability.

\section{References:}


[1]Yu Xu,LiuJi-hong,HeMiao.Computer Integrated Manufacturing Systems. Vol.02(2011), p.225-231.(In Chinese)

[2] Titus Schleyer;Melissa Castine and Miguel Humberto Torres-Urquidy:J Am Dent Assoc. Vol.142(2011),p.250-251.

[3] Carlos Buil-Aranda;MarceloArenas;OscarCorcho;AxelPolleres: Web Semantics: Science, Services and Agents on the World Wide Web.Vol.18(2014), p.1-17.

[4]Delia Rusu;BlažFortuna;DunjaMladenić: Applied Ontology. Vol.9(2014),p.65-95.

[5]Jin Juliang,WeiYiming,PanJinfeng: System Engineering-theory \& Practice, Vol.01(2004), p. 63-69.(In Chinese) 